\title{
A Diagnosis of Rainfall over South America during the 1997/98 El Niño Event. Part II: Roles of Water Vapor Transport and Stationary Waves
}

\author{
V. Brahmananda Rao, Srinivasa R. Chapa, J. P. R. Fernandez, and Sergio H. Franchito \\ Instituto Nacional de Pesquisas Espaciais, Sao Jose dos Campos, Sao Paulo, Brazil
}

(Manuscript received 12 June 2001, in final form 12 June 2001)

\begin{abstract}
A diagnosis of rainfall over South America (SA) during the 1997/98 El Niño year is made examining the roles of water vapor transport and stationary waves. It is found that the low-level jet (LLJ) on the eastern side of the central Andes is stronger during the El Niño event and transports more moisture. This seems to be the source for higher rainfall over southeast SA noted during the El Niño years.

A calculation of three-dimensional stationary wave activity $\left(F_{s}\right)$ for 1997 and 1998 showed that in the summer of 1996/97 stationary waves propagate poleward and eastward from midlatitudes into the higher latitudes to the west of south SA and then propagate equatorward to the east of SA. During the autumn of 1997, the vertical component of $F_{s}$ is consistent with a blocking high over the southeast Pacific. To the east of this high cold air advection from Antarctica occurs, and to the west warm air advection occurs. This is consistent with negative and positive centers seen in the vertical component of $F_{s}$ to the east and west of south SA. The rainfall anomalies during a particular season seem to be due to multiple causes and this complicates a direct connection between them. Although over the southeast of SA, the higher rainfall during 1997 and 1998 can be attributed to some specific causes such as higher water vapor transport by LLJ in summer of 1997/98, in other parts such an association was not possible.
\end{abstract}

\section{Introduction}

Interannual variations of rainfall over several parts of South America (SA) are linked closely to the occurrence of El Niño and La Niña events. Since the early study of Walker (1928), several authors discussed the connection between the El Niño-Southern Oscillation (ENSO) and rainfall over SA (e.g., Aceituno 1988; Rao and Hada 1990; and others). In Part I (Rao et al. 2002), we discussed the characteristics of rainfall over SA in the National Centers for Environmental Predictions-National Center for Atmospheric Research (NCEP-NCAR) reanalysis (Kalnay et al. 1996) and rain gauge data, and examined the rainfall changes during 1997 and 1998. In the Tropics, regions of higher (lower) rainfall are generally associated with convergence (divergence) of water vapor flux. Thus, it would be interesting to study the characteristics of water vapor flux. Quasi-stationary waves influence the rainfall over SA by generating blocking episodes in the southeast Pacific near the west coast of SA. Marques and Rao (2000) found that the occurrence of blocking highs over the southeast Pacific increases during the El Niño events. Rutllant and Fuenzalida (1991) found that the rainfall in Chile during the

Corresponding author address: Dr. V. Brahmananda Rao, Instituto Nacional de Pesquisas Espaciais, CP 515, São José dos Campos, SP 12201-970, Brazil.

E-mail: vbrao@cptec.inpe.br
El Niño events is affected because of blocking. Marques and Rao (1999) noted that blocking over the southeast Pacific strongly influences rainfall over SA. Renwick and Revell (1999) and Rao et al. (2000) showed the importance of quasi-stationary waves forced during the El Niño events in generating blocking events over the southeast Pacific. In this part, we discuss the characteristics of water vapor flux and quasi-stationary waves during 1997 and 1998.

\section{Data sources}

We use the wind (zonal and meridional components, $u$ and $v$ ); specific humidity $q$, temperature $T$, and geopotential $\phi$ data of NCEP-NCAR reanalysis. These data are given on a $2.5^{\circ}$ by $2.5^{\circ}$ latitude and longitude grid and span globally. These data are used to calculate the moisture flux and to identify the source regions of anomalous stationary wave activity. The details of the method of calculation are given in the following sections.

\section{Moisture flux}

The moisture budget equation can be written as

$$
\partial w / \partial t=-\boldsymbol{\nabla} \cdot \mathbf{Q}+E-P
$$

where 

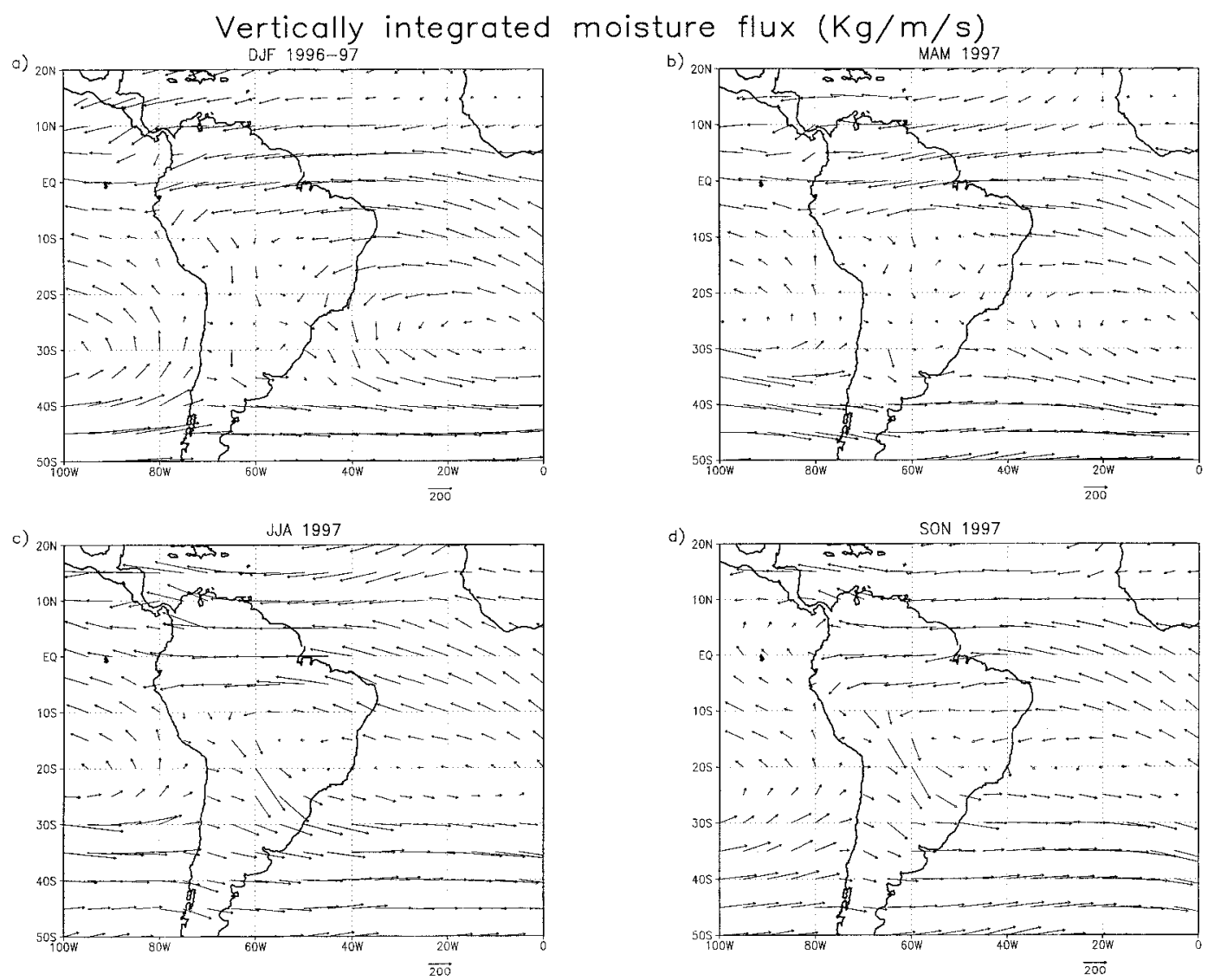

FIG. 1. Seasonal vertically integrated moisture flux $\left(\mathrm{kg} \mathrm{m}^{-1} \mathrm{~s}^{-1}\right)$ for 1997 . The magnitude of the flux is given by the length of arrows. Scale is at bottom of each panel.

$$
\mathbf{Q}=\frac{1}{g} \int_{p_{t}}^{p_{0}} q \mathbf{V} d p
$$

and $p_{t}=300 \mathrm{hPa}, p_{0}=$ surface pressure, $g$ is the acceleration of gravity, and $\mathbf{V}$ is the vector wind. Equation (1) states that the change of total precipitable water $(w)$ in the column is equal to the difference between evaporation $(E)$ and the sum of precipitation $(P)$ and the vertically integrated moisture flux divergence $(\boldsymbol{\nabla} \cdot \mathbf{Q})$. For long-term means $\partial w / \partial t$ is small, then Eq. (1) becomes

$$
E-P=\boldsymbol{\nabla} \cdot \mathbf{Q} .
$$

For estimating vertical integration of moisture flux and its divergence, data at the surface level, 1000, 925, $850,700,600,500,400$, and $300 \mathrm{hPa}$, are used. Since surface data are not available in the pressure level data, sigma 0.995 data are used. Specific humidity at sigma 0.995 is calculated from relative humidity and surface temperature at sigma 0.995 using the Clausius-Clapeyron equation. Vertical integration is done from the surface through $300 \mathrm{hPa}$, instead of from 1000 to $300 \mathrm{hPa}$, to avoid wrong estimates over mountainous regions.

Figures 1, 2, and 3 show, respectively, the vertically integrated moisture flux for 1997, 1998, and the differ- ence between the two. The general characteristics of moisture flux over SA are already discussed by Rao et al. (1996) and Labraga et al. (2000) and here the emphasis is given to the differences between the years 1997 and 1998. During all the four seasons the westward flux of water vapor in the Tropics is noted in both years. This shows the importance of moisture flux by trade winds into the Amazon basin. Also the anticyclonic cell of moisture flux in the subtropical Atlantic Ocean associated with the subtropical high here is clearly seen in all the seasons in both years, although it is stronger in the summer [December-January-February (DJF)]. Associated with this anticyclonic cell southward moisture flux is seen over the southeast coast of Brazil in the summer. The large southward transport of moisture from the Tropics into the subtropics and midlatitudes is seen in all the seasons to the east of central Andes mountains. This is related to the low-level jet (LLJ) noted in this region (Nogués-Paegle and Mo 1997). The moisture flux associated with LLJ is stronger during the summer and autumn seasons of the El Niño year 1998 compared to that in the year 1997. Thus Figs. 3a and $3 \mathrm{~b}$ clearly show the higher southeastward transport. This higher transport associated with a stronger LLJ during 

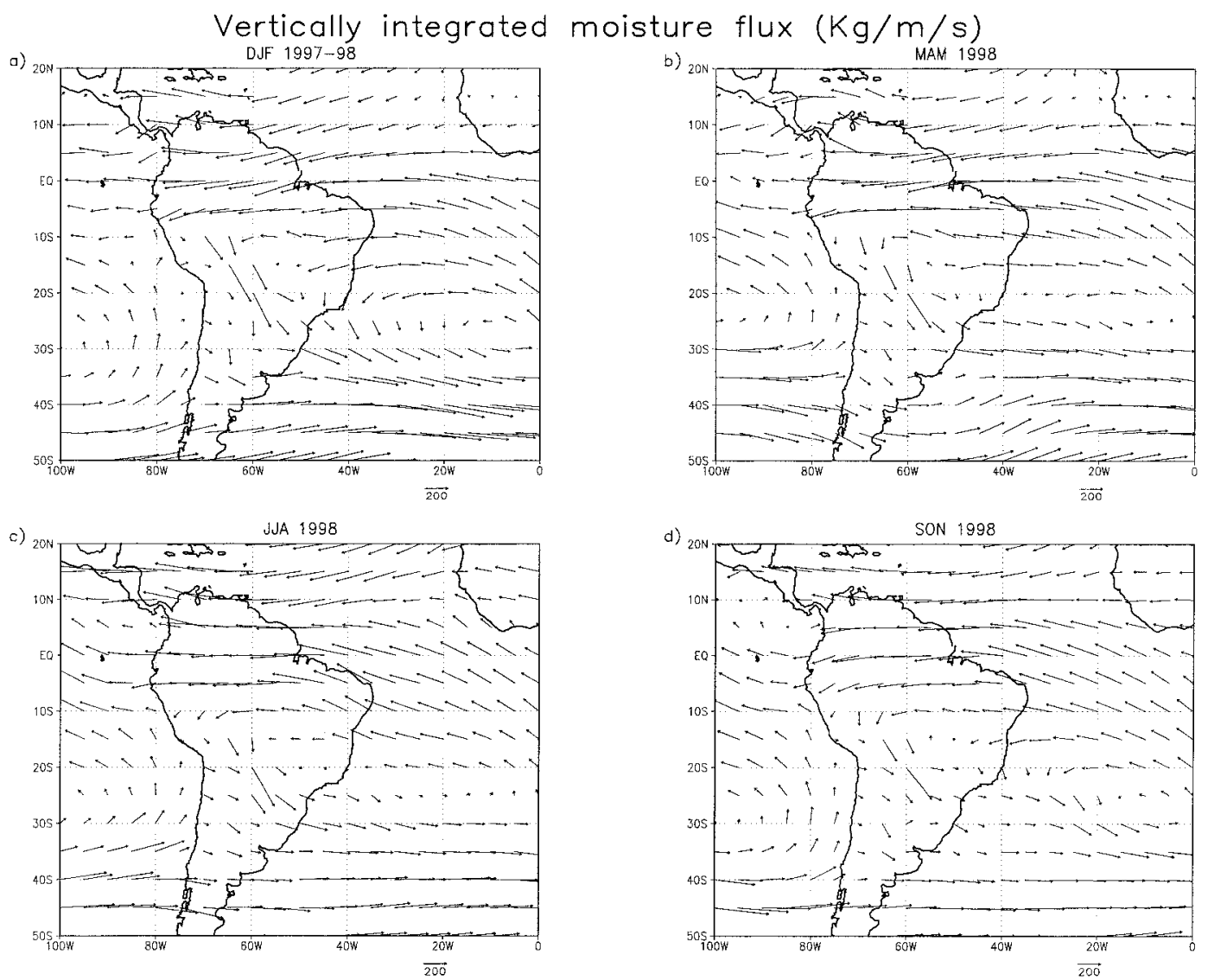

FIG. 2. Same as Fig. 1 but for 1998.

the El Niño years seems to support higher rainfall in the southeast SA noted earlier. The westward flux of water vapor in the Tropics was more in the summer and autumn seasons of 1998 compared to those of 1997.

In the midlatitudes the moisture transport is eastward associated with the westerlies there (Figs. 2 and 3). This transport is higher at $30^{\circ}-40^{\circ} \mathrm{S}$ during DJF and MAM 1998 as shown by the eastward transport in Figs. 3a,b. However, during JJA and SON the difference shows a westward transport over the Atlantic, south SA, and the east Pacific.

Precipitation is mainly maintained by the convergence of water vapor flux. The increase (decrease) of precipitation is closely related to the enhancement (reduction) of convergence of water vapor flux. Thus, the differences in the divergence of water vapor flux between the two years, 1997 and 1998 (Fig. 4) are examined. A comparison between Fig. 7 (of Part I) and Fig. 4 (Part II) shows that the negative (positive) values in Fig. 7 (Part I) correspond in general with the positive (negative) values in Fig. 4 (Part II). The agreement is better in the summer and autumn seasons. The higher divergence of water vapor flux over northeast Brazil in MAM 1998 seen in Fig. 4b was associated with the severe drought conditions over this region. In the winter and spring seasons the differences in the divergence of water vapor flux (Figs. 4c and 4d) show finer details that are not seen in Fig. 7 (Part I). From Eq. (3) the differences in the divergence of water vapor flux and precipitation are due to evaporation. However, this is valid for observations and numerical simulations. When the fields $Q, E$, and $P$ are produced with a data assimilation system, such as the NCEP-NCAR reanalysis, the correct budget equation is given by (Schubert et al. 1995)

$$
\boldsymbol{\nabla} \cdot \mathbf{Q}=E-P+D_{c},
$$

where $D_{c}$ represents the increment to the model state by the observational data $(\boldsymbol{\nabla} \cdot \mathbf{Q}$ and $P)$. Here, for the sake of brevity, $D_{c}$ is not discussed.

Figure 5 shows the difference in evaporation between 1998 and 1997. Except in the summer, the evaporation over the Atlantic Ocean from about $10^{\circ} \mathrm{N}$ to $30^{\circ} \mathrm{S}$ is higher in 1998. South of about $30^{\circ} \mathrm{S}$ the reverse is true. But in summer, the evaporation was higher in 1997 in the Atlantic near the coast of Brazil. The higher rainfall over south Brazil noted earlier during 1998 seems to be supported by higher evaporation over the subtropical Atlantic and higher moisture flux particularly associated with stronger LLJ. Over the equatorial east Pacific, negative values are seen in Fig. 5 showing that the evaporation was higher in 1997. These higher values seem 

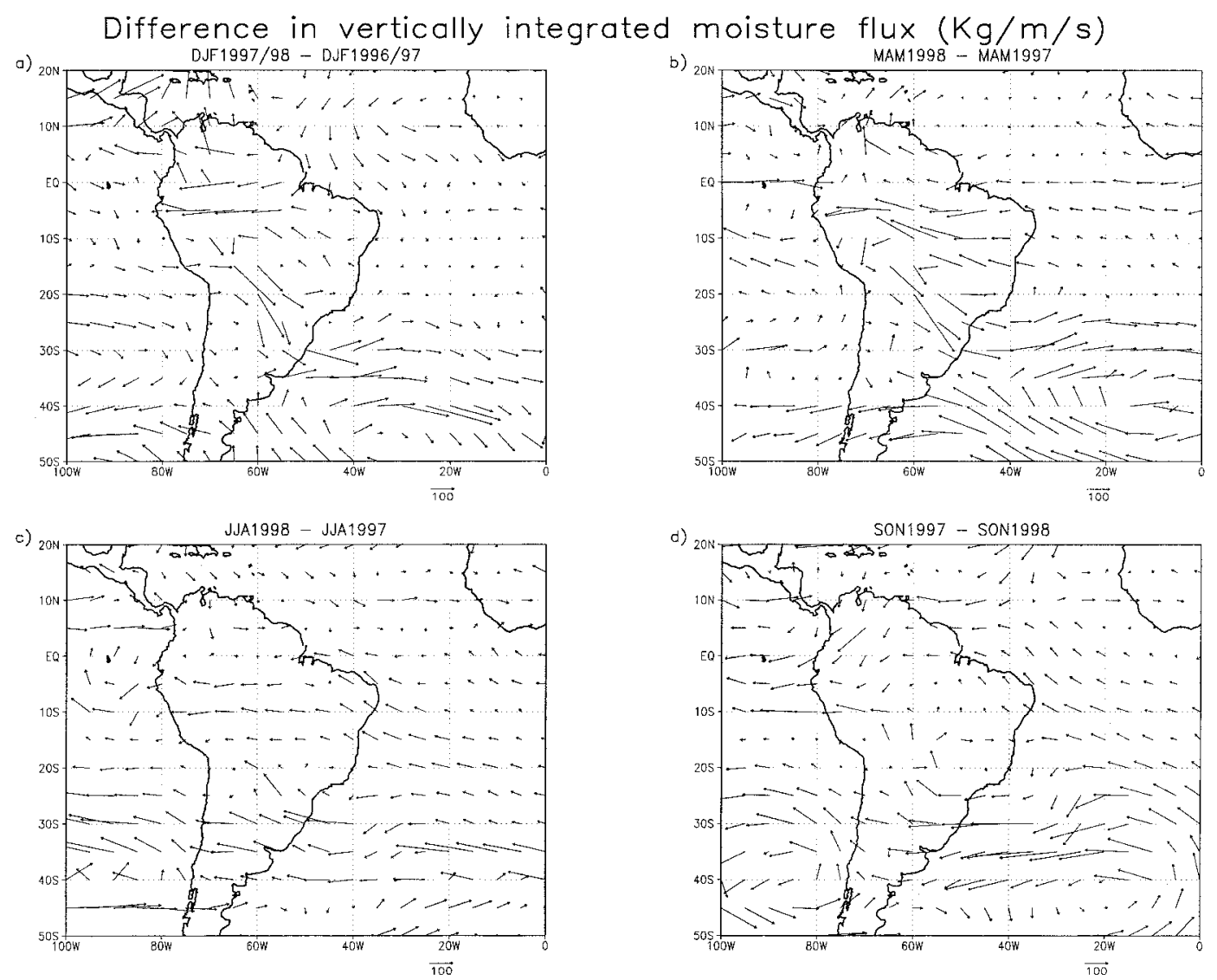

FIG. 3. Difference in vertically integrated moisture flux $\left(\mathrm{kg} \mathrm{m}^{-1} \mathrm{~s}^{-1}\right)$ between 1998 and 1997.

to be associated with higher SST in the equatorial east Pacific. South of these negative values, positive values are seen in Fig. 5.

\section{Quasi-stationary waves}

As mentioned in the introduction, quasi-stationary waves influence the rainfall over SA. Here we will use the approach introduced by Plumb (1985) to study quasi-stationary waves. Although we are interested primarily in the influence of quasi-stationary waves over SA, we study quasi-stationary waves over the entire Southern Hemisphere. The approach introduced by Plumb (1985) has been extensively used in both model and observational studies (Plumb 1985; Mo et al. 1987; Karoly et al. 1989; Lau and Peng 1992; Schubert et al. 1993; Quintanar and Mechoso 1995).

For small-amplitude waves on a zonal mean flow, the conservation relationship for stationary wave activity (Plumb 1985) may be written as

$$
\partial A_{s} / \partial t+\boldsymbol{\nabla} \cdot \mathbf{F}_{s}=C_{s},
$$

where $A_{s}$ is the stationary wave activity,

$$
A_{s}=\frac{1}{2} p\left[\frac{\bar{q}^{* 2}}{\frac{1}{a \sin \varphi} \frac{\partial(\bar{Q} \sin \varphi)}{\partial \varphi}}\right]+p \frac{E}{\bar{U}}
$$

Here $\mathbf{F}_{s}$ is the three-dimensional flux of stationary wave activity,

$$
\begin{aligned}
\mathbf{F}_{s}=p \cos \varphi\{ & \bar{v}^{* 2}-\frac{1}{2 \Omega a \sin 2 \varphi} \frac{\partial\left(\bar{v}^{*} \bar{\phi}^{*}\right)}{\partial \lambda},-\bar{u}^{*} \bar{v}^{*} \\
& -\frac{1}{2 \Omega a \sin 2 \varphi} \frac{\bar{\partial}\left(\bar{u}^{*} \bar{\phi}^{*}\right)}{\partial \lambda}, \frac{2 \Omega \sin \varphi}{S} \\
& \left.\times\left[\bar{v}^{*} \bar{T}^{*}-\frac{1}{2 \Omega a \sin 2 \varphi} \frac{\partial\left(\bar{T}^{*} \bar{\phi}^{*}\right)}{\partial \lambda}\right]\right\}
\end{aligned}
$$

and $C_{s}$ is a nonconservative source-sink term that includes diabatic and frictional effects and interactions with transient eddies. The overbar represents a time average and the quantities with asterisks denote departures from the zonal average; $p$ is the pressure, $Q$ and $q^{*}$ are the zonal mean and perturbation quasigeostrophic potential vorticity, $U$ is the zonal mean flow, $E$ is the wave energy density, $u^{*}$ and $v^{*}$ are the eddy zonal and me- 

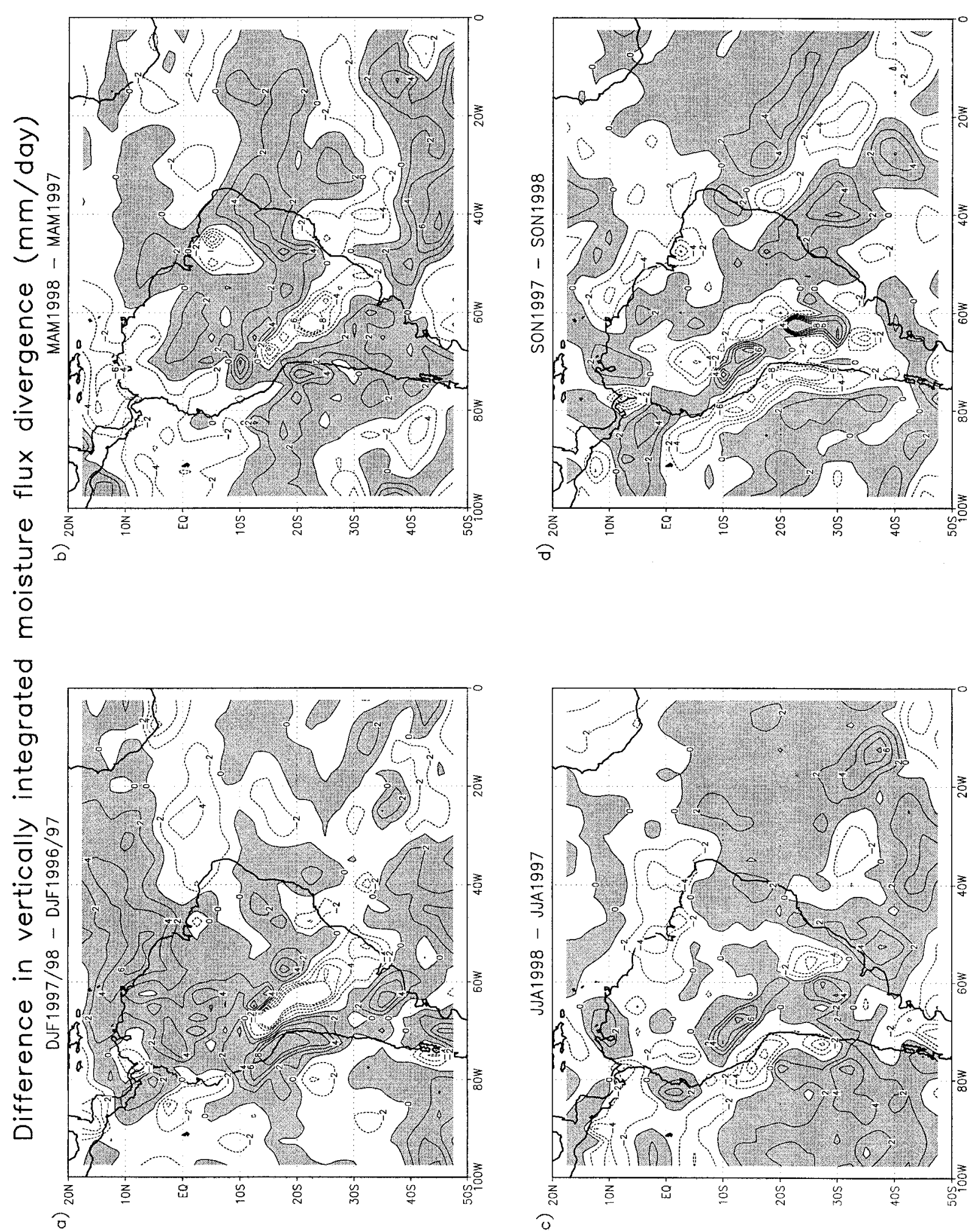

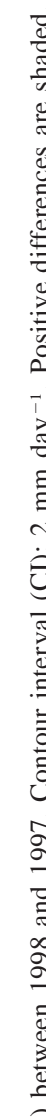

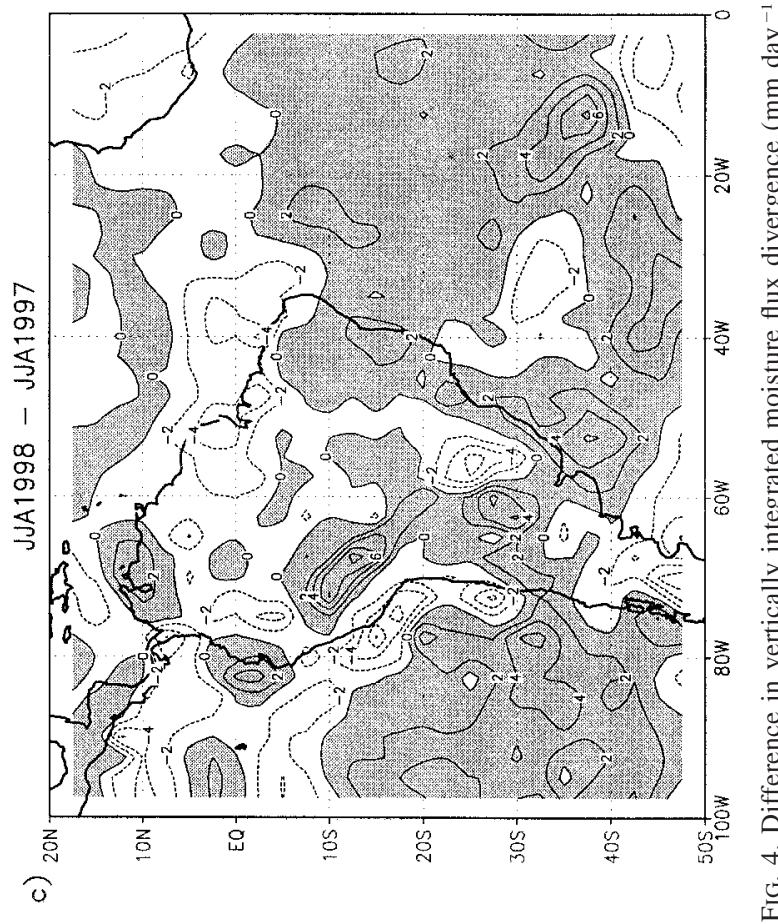



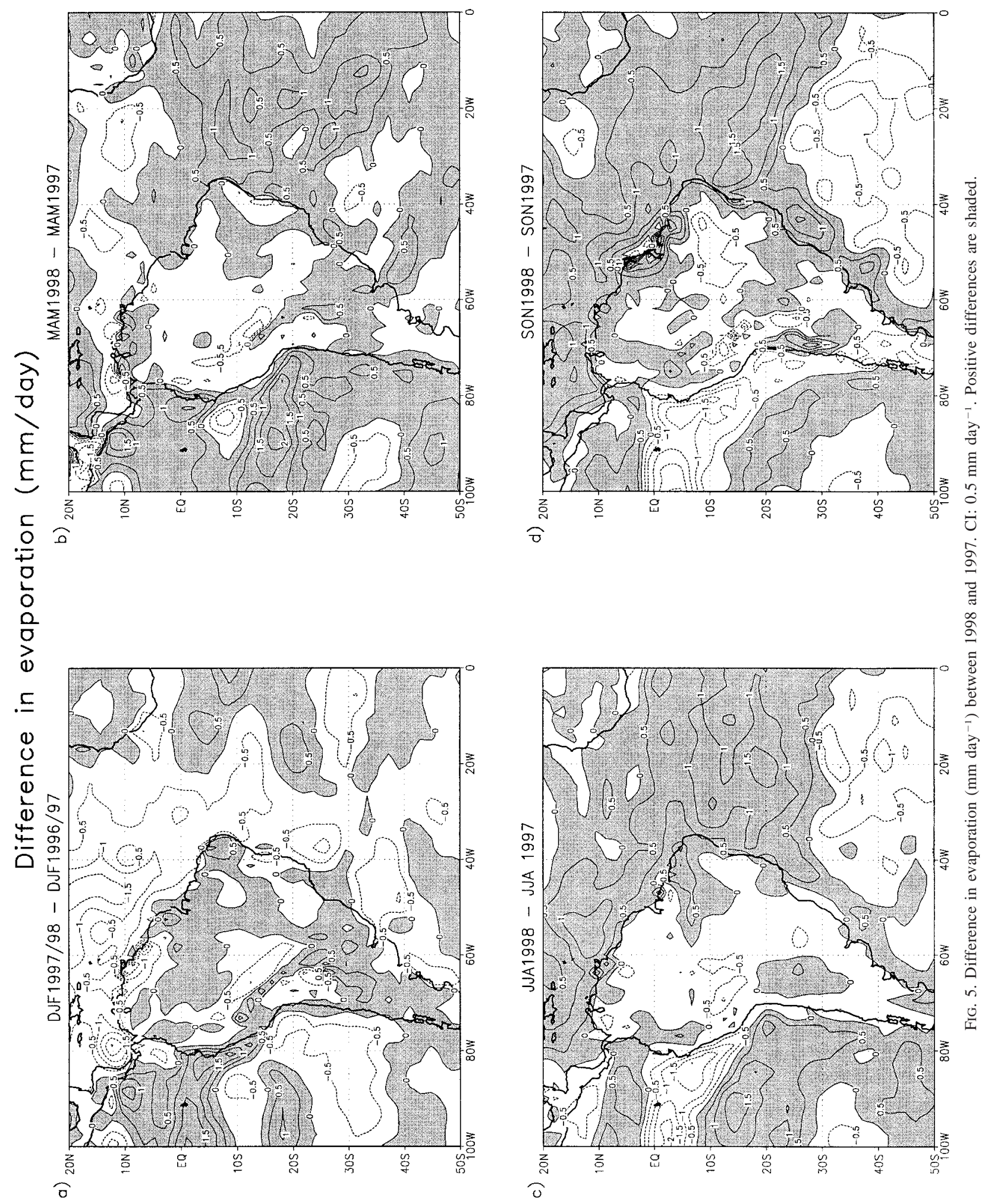

$\frac{0}{0}$
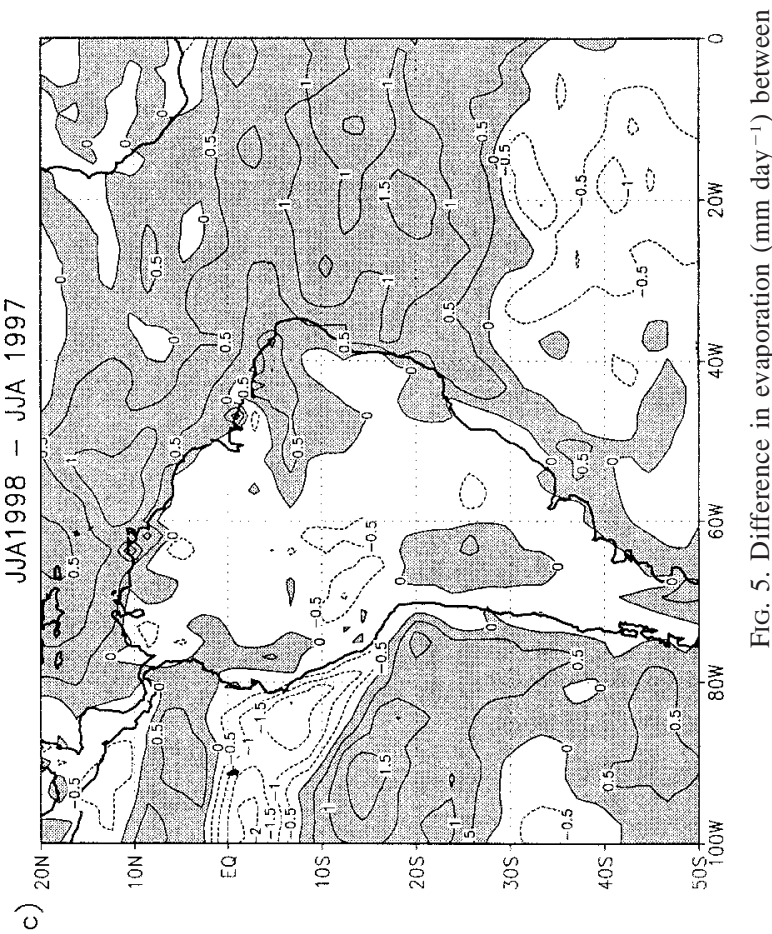
ridional geostrophic wind components, $a$ is the earth's radius, $\phi$ is the geopotential, $T$ is the temperature, $\Omega$ is the angular rotation rate of the earth, and $S$ is a timeand area-averaged static stability.

Plumb (1985) showed that for steady, conservative waves $\mathbf{F}_{s}$ is nondivergent and that for slowly varying almost plane waves, $\mathbf{F}_{s}$ is parallel to the group velocity. In general, the starred (wave) quantities are evaluated from time averages (a season) in which case the time derivative in expression (5) is relatively small and wave sources (sinks) are associated with regions where $\mathbf{F}_{s}$ is divergent (convergent).

Since $\mathbf{F}_{s}$ is derived under quasigeostrophic assumption, its validity is questionable in low latitudes and also one should be careful in interpreting the short-scale quasi-stationary waves (Quintanar and Mechoso 1995).

Figures 6 and 7 show the horizontal and vertical components of $\mathbf{F}_{s}$ for 1997 and 1998, respectively. Horizontal components are shown as vectors and vertical components as contours. The distribution of horizontal components $(\mathrm{Hc})$ of $\mathbf{F}_{s}$ in Fig. 6a shows that in DJF quasi-stationary waves propagate poleward and eastward from midlatitudes into higher latitudes to the southwest of SA and then are refracted equatorward to the east of SA. The distribution of vertical component $(\mathrm{Vc})$ of $\mathbf{F}_{s}$ in this region shows negative values over the southern tip of SA and positive values to the southwest. This is consistent with the height anomaly (figure not shown) that shows a high in this region. Thus, to the east of this high cold air advection from Antarctica is expected and to the west warm air advection occurs, thus provoking the negative values of $\mathrm{Vc}$ to the east and positive $\mathrm{Vc}$ to west. Wave propagation from the midlatitudes to the Tropics is seen to the east of Australia and in this region positive values of $\mathrm{Vc}$ are seen. By MAM (Fig. 6b) Hc becomes stronger and shifts westward compared to DJF. In the winter (Fig. 6c) the Hc decreases in intensity. But Vc increases substantially and a strong positive center is found over south SA. As mentioned by Mo et al. (1987), Vc tends to be strongly positive over the region of intense precipitation. Figure 7c (Part I) shows negative values in this region, that is, rainfall was higher in JJA 1997 than in JJA 1998. (See also Figs. 58 and 59 of Bell and Halpert 1998.)

Figure $6 \mathrm{~d}$ shows that there is a strong negative center of $\mathrm{Vc}$ of $\mathbf{F}_{s}$ over south SA and a positive center to the west. The 300-hPa height anomaly (SON 1997 minus normal) shows (figure not shown) the positive and negative anomaly centers suggesting Rossby wave propagation from the tropical central Pacific to the east and then to lower latitudes with a positive anomaly center over the southeast of SA, in a way very similar to what was found by Rao et al. (2000). This wave propagation is consistent with $\mathbf{F}_{s}$ vectors seen in Fig. 6d. The high (positive anomaly) to the southwest of SA is indicative of recurrent blocking in this region (Bell and Halpert 1998). SON is the favorable season of blocking in this region (Marques and Rao 2000; Rao et al. 2000). To the east of this blocking high, cold air advection from Antarctica is expected and to the west warm air advection occurs. This is consistent with the negative and positive centers of $300-\mathrm{hPa}$ anomalies (figure not shown) near south SA.

Figure 7 shows the vertical and horizontal components of $\mathbf{F}_{s}$ for 1998. The year 1998 saw both extremes of the ENSO cycle with one of the strongest El Niño episodes in the historical record continuing from January to early May and La Niña conditions occurring from July to December. In the eastern subtropical Pacific strong equatorial propagation of quasi-stationary waves is seen (Fig. 7a). Also strong divergence of vectors in this region show a source of stationary waves, obviously associated with SST anomalies. To the south of this region a weak zonal propagation of stationary waves is seen. In the region of diverging vectors a positive center of $\mathrm{Vc}$ is seen, which is not necessarily associated with heat transports. In MAM 1998, poleward propagation of quasi-stationary waves is seen to the west of SA. By JJA 1998, the propagation of quasi-stationary waves in the mid- and high latitudes decreases. In SON, to the southeast of SA a negative 300-hPa high anomaly (figure not shown) is seen. During the El Niño SON 1997, as mentioned earlier, a high is seen. The low in this region during La Niña SON 1998 reduces the occurrence of blocking in this region (Marques and Rao 2000; Rao et al. 2000) The configuration of $\mathrm{Vc}$ of $\mathbf{F}_{s}$ is generally opposite to what is observed in SON 1997. To the southwest of SA equatorial propagation of quasi-stationary waves is seen and the vectors diverge suggesting a source of quasi-stationary waves. In this season, to the east of Australia and New Zealand also equatorial wave propagation of quasi-stationary waves is seen and a source of quasi-stationary waves can also be inferred here. In many other regions of Figs. 6 and 7, a source region of quasi-stationary can be inferred to the east of Australia and New Zealand.

\section{Conclusions}

A diagnosis of rainfall characteristics over SA during the 1997/98 El Niño event is made. The large southward transport of moisture from the Tropics into the subtropics and midlatitudes to the east of the Andes is associated with the LLJ. This LLJ is stronger during the 1997/98 El Niño event. Higher transport of moisture associated with stronger LLJ seems to support higher rainfall over southeast SA during El Niño events. In general, higher (lower) precipitation seems to be supported with higher (lower) convergence of water vapor flux. The difference between the divergence of water vapor transport and precipitation is due to evaporation. The higher rainfall over southeast SA in 1997/98 seems to be supported by higher evaporation over subtropical South Atlantic and higher moisture flux associated with stronger LLJ. The severe drought over northeast Brazil (NEB) during MAM 1998 was associated with diver- 


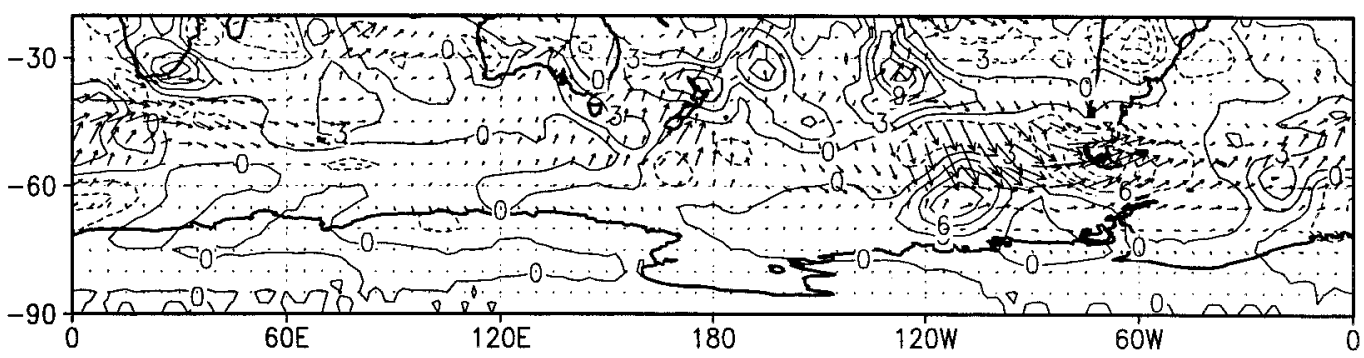

(a)

$\overrightarrow{10}$

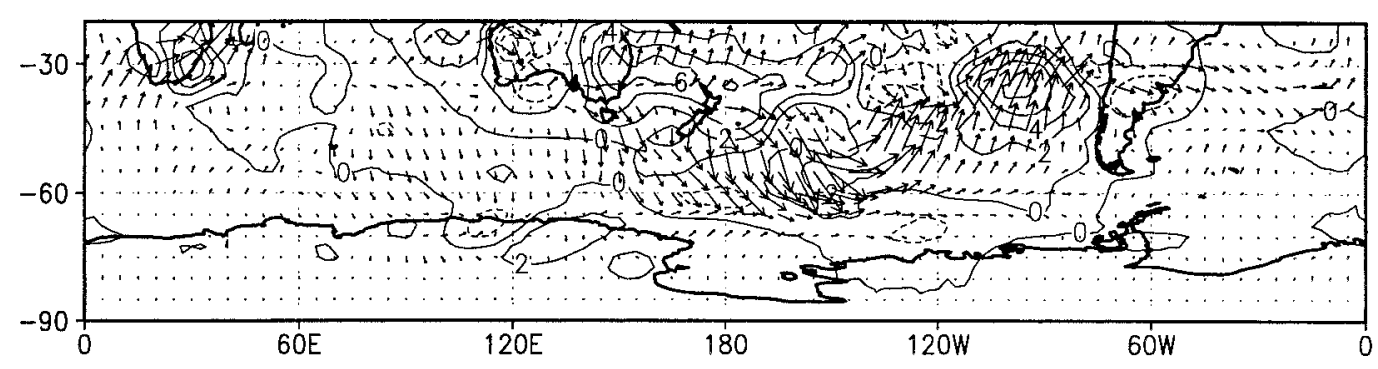

(b)

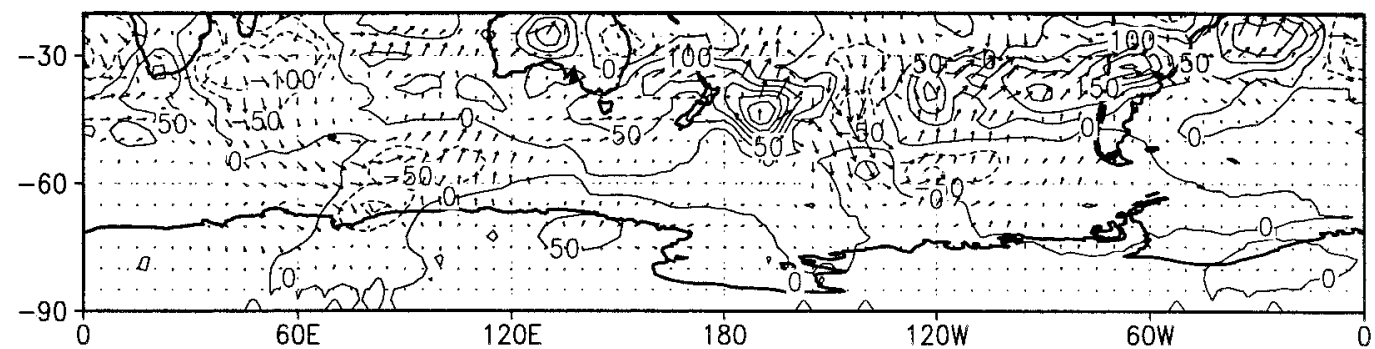

(c)

$\overrightarrow{10}$

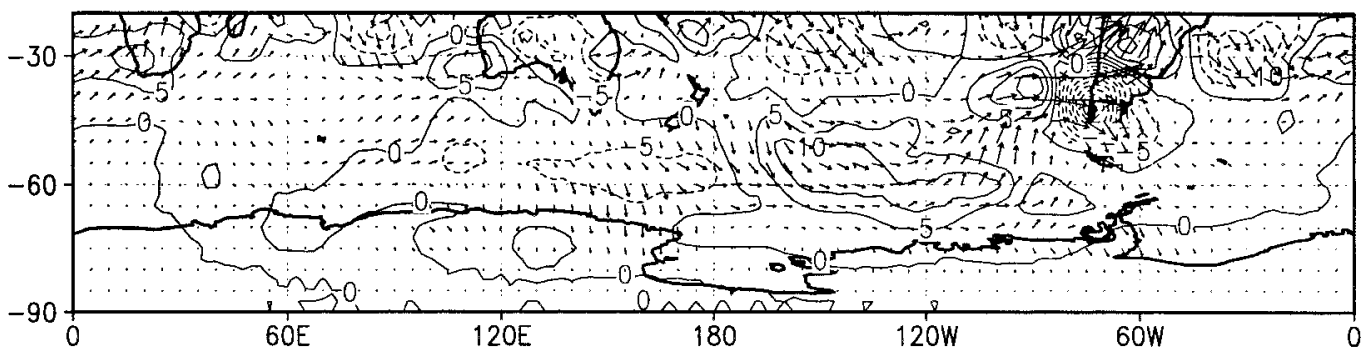

(d)

FIG. 6. Wave activity $\left(\mathbf{F}_{s}\right.$ ) for: (a) DJF, (b) MAM, (c) JJA, and (d) SON for 1997. The reference arrow is $10 \mathrm{~m}^{2}$ $\mathrm{s}^{-2}$. Contours represent vertical component of $\mathbf{F}_{s}\left(\mathrm{~m}^{2} \mathrm{~s}^{-2}\right)$.

gence of vertically integrated water vapor flux. This divergence of water vapor flux, together with sinking motion over NEB seems to be responsible for the intense drought conditions during MAM 1998.
A calculation of $\mathbf{F}_{s}$, the three-dimensional stationary wave activity for 1997 and 1998 showed that in summer of 1996/97 stationary waves propagate poleward and eastward from midlatitudes into higher latitudes to 


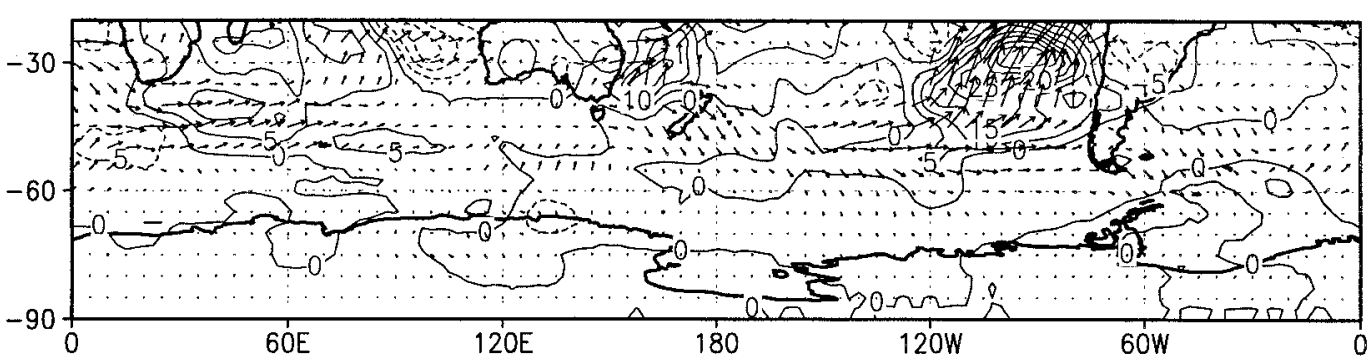

(a)

$\overrightarrow{10}$

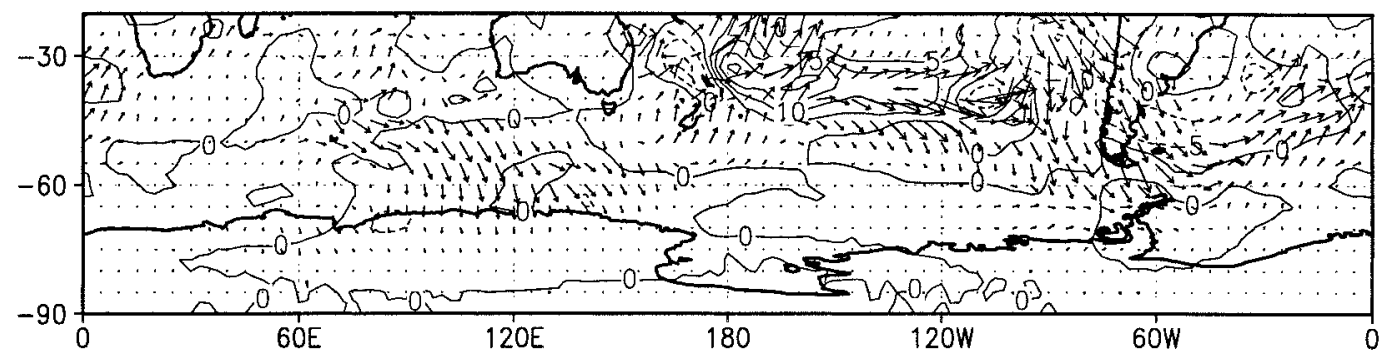

(b)

$\overrightarrow{10}$

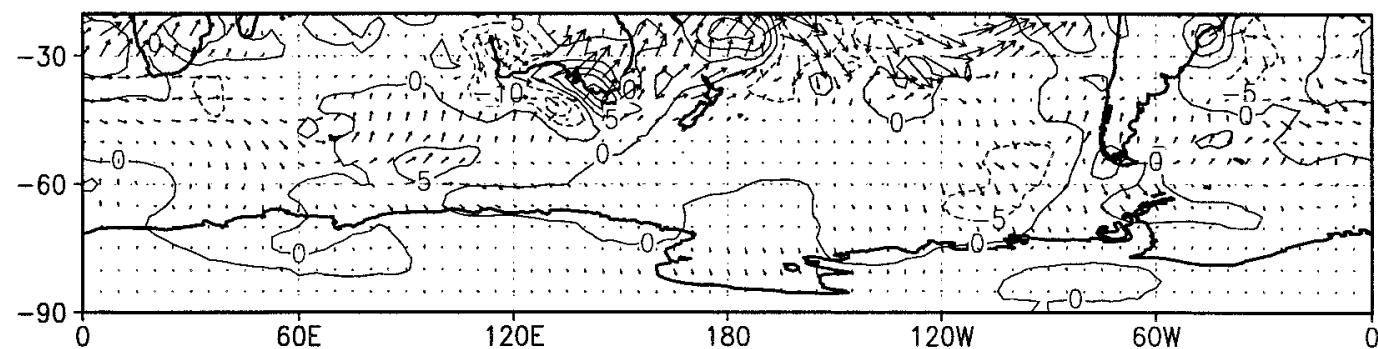

(c)

$\overrightarrow{10}$

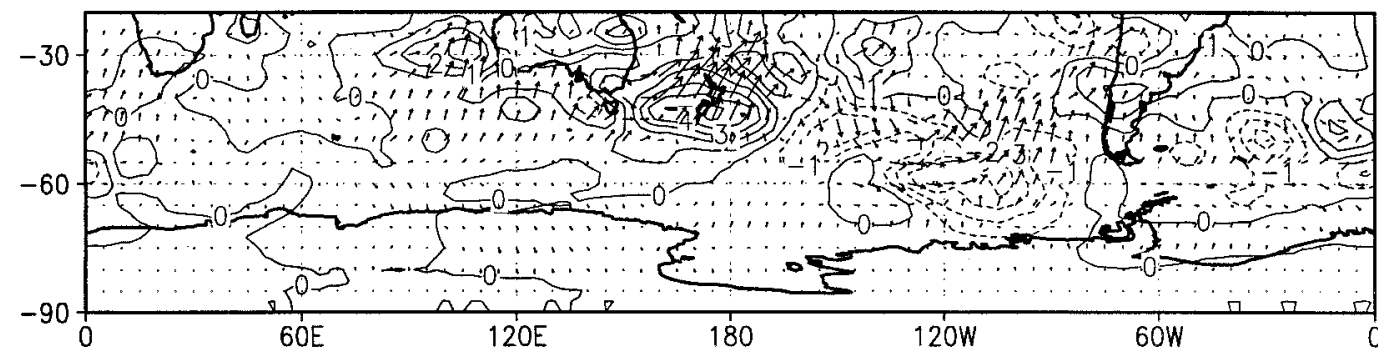

(d)

FIG. 7. Same as Fig. 6 but for 1998 .

southwest SA and then propagate equatorward to the east of SA. During SON 1997, the vertical component of $\mathbf{F}_{s}$ is consistent with a blocking high over the southeast Pacific. To the east of this high cold air advection from Antarctica is expected and to the west warm air advection occurs. This is consistent with negative and positive centers seen in the vertical component of $\mathbf{F}_{s}$ to the east and southwest of SA. During the summer of 1997/98, strong divergence of the horizontal component of $\mathbf{F}_{s}$ is seen in the eastern subtropical Pacific, sug- 
gesting a source of stationary waves obviously associated with positive SST anomalies. During the La Niña period of SON 1998 opposite characteristics (to what happened in SON 1997) consistent with a low in the southeast Pacific occurred. These high and low pressure centers over the southeast Pacific during the El Niño and La Niña events favor higher and lower blocking frequency in this region associated with stationary wave activity forced by positive and negative SST anomalies (Renwick and Revell 1999; Rao et al. 2000). Higher or lower frequency of blocking in the southeast Pacific has a severe impact on the rainfall over SA causing higher rainfall over subtropical SA and lower rainfall over higher latitudes.

Acknowledgments. We are grateful to Prof. S. Hastenrath for his constructive criticism. NCEP-NCAR reanalysis data were provided by the NOAA-CIRES Climate Diagnostics Center, Boulder, Colorado, from their site online at http://www.cdc.noaa.gov/. Rain gauge data from Brazil were obtained from ANEEL (Agência Nacional de Energia Elétrica). J. P. R. Fernandez is supported by Fundação de Amparo à Pesquisa do Estado de São Paulo.

\section{REFERENCES}

Aceituno, P., 1988: On the functioning of the Southern Oscillation in the South America sector. Part I: Surface climate. Mon. Wea. Rev., 116, 505-524.

Bell, G. D., and M. S. Halpert, 1998: Climate assessment for 1997. Bull. Amer. Meteor. Soc., 79, S1-S50.

Kalnay, E., and Coauthors, 1996: The NCEP/NCAR 40-Year Reanalysis Project. Bull. Amer. Meteor. Soc., 77, 437-471.

Karoly, D. J., R. A. Plumb, and M. Ting, 1989: Examples of horizontal propagation of quasi-stationary waves. J. Atmos. Sci., 46, 28022811

Labraga, J. C., O. Frumento, and M. Lopez, 2000: The atmospheric water vapor cycle in South America and the tropospheric circulation. J. Climate, 13, 1899-1915.
Lau, K.-M., and L. Peng, 1992: Dynamics of atmospheric teleconnections during the northern summer. J. Climate, 5, 140-158.

Marques, R. F. C., and V. B. Rao, 1999: A diagnosis of a long-lasting blocking event over the Southeast Pacific Ocean. Mon. Wea. Rev., 127, 1761-1775.

- , and - 2000: Interannual variations of blockings in the Southern Hemisphere and their energetics. J. Geophys. Res., 105 (D4), 4625-4636.

Mo, K. C., J. Pfaendtner, and E. Kalnay, 1987: A GCM study on the maintenance of the June 1982 blocking in the Southern Hemisphere. J. Atmos. Sci., 44, 1123-1142.

Nogués-Paegle, J., and K. C. Mo, 1997: Alternating wet and dry conditions over South America during summer. Mon. Wea. Rev., 125, 279-291.

Plumb, R. A., 1985: On the three-dimensional propagation of stationary waves. J. Atmos. Sci., 42, 217-229.

Quintanar, A. L., and C. R. Mechoso, 1995: Quasi-stationary waves in the Southern Hemisphere. Part I: Observational data. J. Climate, 8, 2659-2672.

Rao, V. B., and K. Hada, 1990: Characteristics of rainfall over Brazil: Annual variations and connections with the Southern Oscillation. Theor. Appl. Climatol., 42, 81-91.

- I. F. A. Cavalcanti, and K. Hada, 1996: Annual variation of rainfall over Brazil and water vapor characteristics over South America. J. Geophys. Res., 101, 26 539-26 551.

- S. H. Franchito, and J. P. R. Fernandez, 2000: Comments on "Blocking over the South Pacific and Rossby wave propagation." Mon. Wea. Rev., 128, 4160-4161.

_ C. C. E. Santo, and S. H. Franchito, 2002: A diagnosis of rainfall over South America during the 1997/98 El Niño event. Part I: Validation of NCEP-NCAR reanalysis rainfall data. J. Climate, 15, 502-511.

Renwick, J. A., and M. J. Revell, 1999: Blocking over the South Pacific and Rossby wave propagation. Mon. Wea. Rev., 127, 2233-2247.

Rutllant, J., and H. Fuenzalida, 1991: Synoptic aspects of the central Chile rainfall variability associated with the Southern Oscillation. Int. J. Climatol., 11, 63-76.

Schubert, S. D., M. Suarez, C.-K. Park, and S. Moorthi, 1993: GCM simulations of intraseasonal variability in the Pacific/North American region. J. Atmos. Sci., 50, 1991-2007.

— C. C. K. Park, R. B. Rood, C. Y. Wu, R. W. Higgins, Y. Kodratiyeva, A. Molod, and T. Takacs, 1995: A multi-year assimilation with the GOES-1 system: An overview and results. NASA Tech. Memo. 104604, 183 pp.

Walker, G. T., 1928: Ceará (Brazil) famines and the general air movement. Beitr. Phys. Frain. Atmos., 14, 88. 